\title{
A xanthogranulomatous process resembling residual disease on end- of-treatment 18f-FDG-PET/CT and Whole Body Magnetic Resonance performed on a primary breast lymphoma treated by ibrutinib plus rituximab-chop
}

\author{
D. ALBANO 1 , C. PATTI ${ }^{2}$, P. ALONGI ${ }^{3}$, A. BRUNO 1 , G. DI BUONO ${ }^{4}$, A. MULÈ $^{2}$, \\ E. GULOTTA ${ }^{4}$, A. AGRUSA ${ }^{4}$, R. IENZI'1 , R. LAGALLA ${ }^{1}$, M. GALIA ${ }^{1}$
}

\begin{abstract}
SUMMARY: A xanthogranulomatous process resembling residual disease on end-of-treatment 18f-FDG-PET/CT and Whole Body Magnetic Resonance performed on a primary breast lymphoma treated by ibrutinib plus rituximab-chop.
\end{abstract}

D. Albano, C. Patti, P. Alongi, A. Bruno, G. Di Buono, A. Mulè, E. Gulotta, A. Agrusa, R. Ienzi, R. Lagalla, M. Galia

We report the case of a woman, affected by breast diffuse large B-Cell lymphoma, who developed a xanthogranulomatous process wrongly interpreted as residual disease on 18F-FDG-PET/CT and Whole Body Magnetic Resonance after treatment with ibrutinib plus standard immunochemotherapy. Newer drugs, such as immunomodulatory agents and checkpoint inhibitors, have demonstrated high effectiveness on lymphoma, but are associated with unclear imaging features such as tumor flare or pseudo-progression, related to inflammatory reactions. Wide imaging techniques availability improves diagnostic possibilities. However, the awareness of the adopted treatment strategy and its possible implications on imaging features is crucial to make a correct response assessment.

KeY Words: Breast lymphoma - FDG-PET/CT - Whole Body Magnetic Resonance Xantogranulomatous process - Ibrutinib - Rituximab.

\section{Introduction}

Primary breast lymphoma is very rare with a prevalence ranging from 0.04 to $0.5 \%$ of breast neoplasms (1). The most frequent histologic type is Diffuse Large B-Cell Lymphoma (DLBCL), usually occurring as unilateral mass, indistinguishable from a breast carcinoma $(1,2)$. The diagnosis of lymphoma is obtained by pathologist through the evaluation of morphology and immunohistochemistry of bioptic specimen of locations of disease. Combined 18F-fluorodeoxyglucose-Positron Emission Tomography/Computed Tomography (FDG-PET/CT) is applied in several oncologic fields (3-7), especially in lymphoproliferative

Department of Radiology, DIBIMED, University of Palermo, Palermo, Italy Department of Hematology I, "Azienda Ospedali Riuniti Villa Sofia-Cervello", Palermo, Italy

Department of Radiological Sciences, Nuclear Medicine Unit, San Raffaele G. Giglio Institute, Cefalù, Italy

${ }^{4}$ Department of General Surgery and Emergency, University of Palermo, Palermo, Italy

Corresponding authors: Giuseppe Di Buono, e-mail: giu.dibuono@gmail.com; Domenico Albano, e-mail: albanodomenico@me.com

(C) Copyright 2016, CIC Edizioni Internazionali, Roma disorders (3); indeed, it is recommended both for staging after diagnosis and for end-of-treatment assessment of DLBCL (8). Whole Body Magnetic Resonance (WBMR) with diffusion-weighted imaging (DWI) is a technique more and more applied in general, urgent (912) and oncologic fields, especially in lymphoma and myeloma patients (13-17). Regarding the role of WBMR in the evaluation of response to therapy there are promising preliminary results but larger studies are necessary to validate its reliability (18). We report the case of a 40-year-old woman, affected by primary breast DLBCL, who developed a xanthogranulomatous process wrongly interpreted as residual disease on FDGPET/CT and WB-MR after treatment with ibrutinib plus standard immunochemotherapy.

\section{Case presentation}

A 40-year-old female patient on May 2015 developed a right breast mass without skin changes, nipple retraction or systemic symptoms. A mammography was performed displaying a large mass, oval in shape, with no evidence of calcifications, greater than $4 \mathrm{~cm}$ in diameter. It was confirmed by ultrasound, which showed 

performed on a primary breast lymphoma treated by ibrutinib plus rituximab-chop

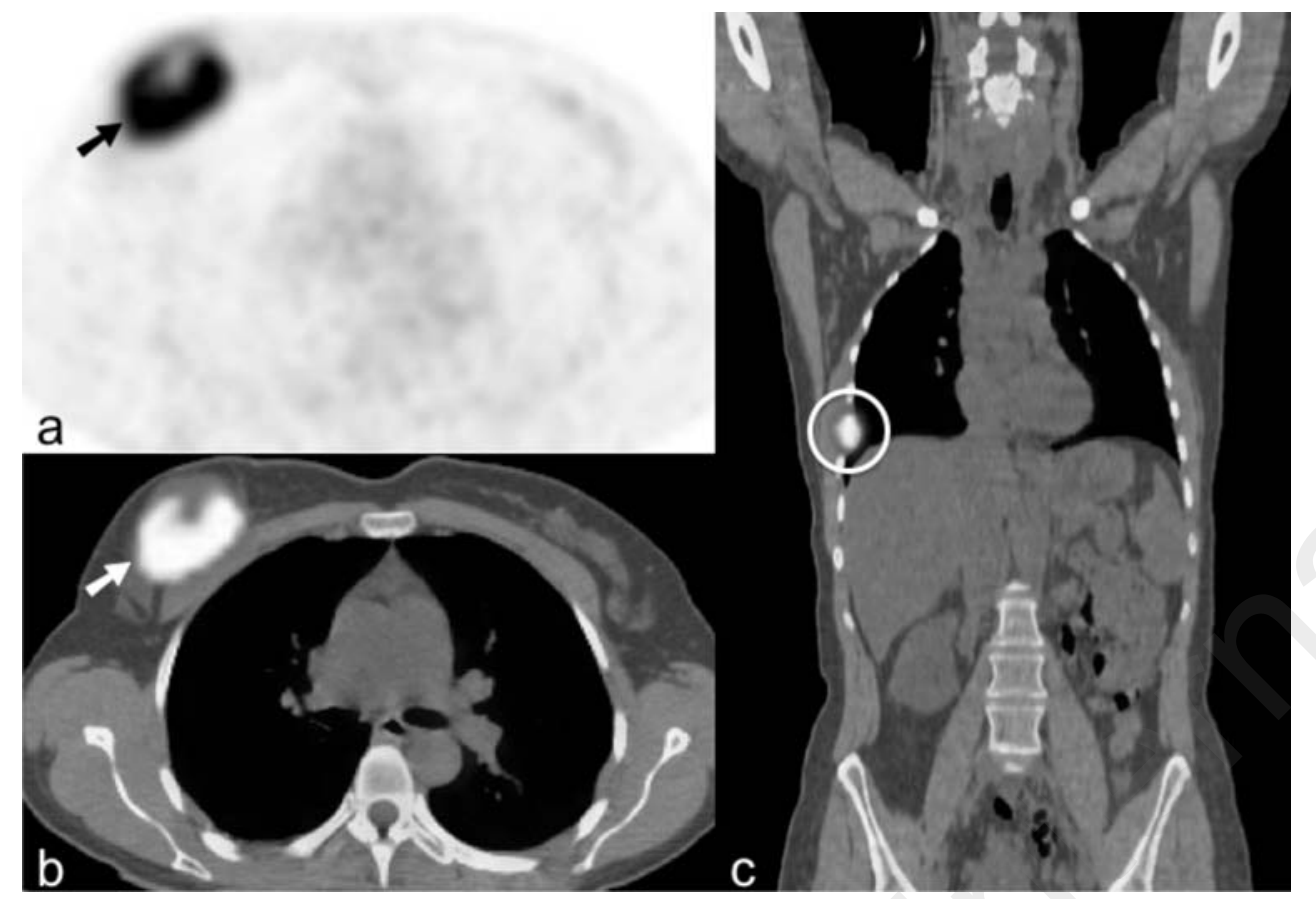

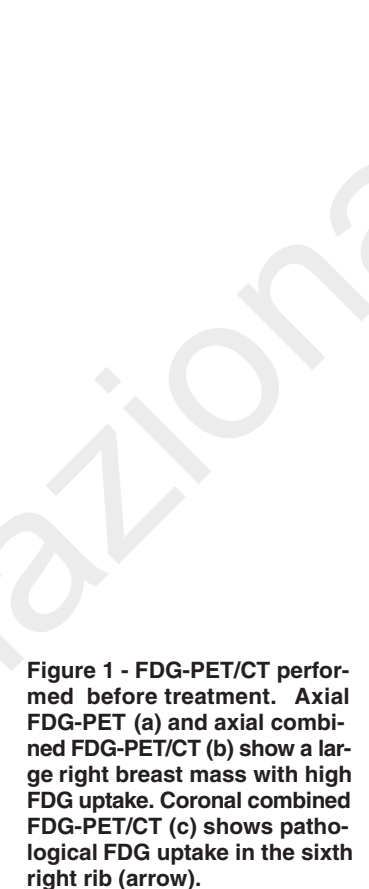

logical FDG uptake in the sixth a solid hypoechoic mass, with lobulated margins and poor vascularity on power-Doppler. An ultrasoundguided breast core biopsy was performed and the histologic and immunohistochemical features led to the diagnosis of DLBCL non-germinal centre type (19) CD20+, BCL2+, BCL6 +, CD5-, MUM1+, CD10-, CD30-, Ki67 90\%. Hence, she was admitted to the haematology department and underwent FDG-PET/CT (Figure 1), which revealed a large breast mass with high FDG uptake (maximum standard uptake value=SUVmax 28) and other pathological FDG uptakes in a right axillary lymph node (SUVmax 4.7) and in the sixth right rib (SUVmax 18.6). Then, the patient performed contrast enhanced CT and unenhanced WB-MR (Figure 2) that confirmed the locations of disease. On July of the same year the patient accepted to participate in a clinical trial for patients with DLBCL non-germinal centre type that combined ibrutinib with the standard immunochemotherapy with rituximab plus cyclophosphamide-doxorubicin-vincristine-prednisolone (CHOP). Thus, she started to receive ibrutinib plus 6 courses of rituximab plus 6 of CHOP. On November, FDG-PET/CT was performed six weeks after the end of therapy. It showed a pathological FDG uptake in a small nodule within the right mammary gland (SUVmax of about 5.4, Deauville score 4) suspicious for residual disease, without any other sites with pathological FDG uptake (Figure 3). The suspect was confirmed by WB-MR which demonstrated the disappear of right axillary lymph node and rib lesion and the reduction in size of the right breast nodule that showed a diameter of $1.3 \mathrm{~cm}$ and a restricted pattern of diffusion on apparent diffusion coefficient (ADC) map (Figure 4). On December, the patient performed an ultrasound displaying a residual inhomogeneously hypoechoic breast nodule that was biopsied (Figure 5). The diagnosis was xanthogranulomatous process mostly consisting of foamy macrophages, in absence of residual pathological lymphomatous cells. On January of the next year, the patient was also treated by radiotherapy with a breast irradiation consisting of a total dose of 30.6 Gy. FDG-PET/CT performed three months after the end of radiotherapy was negative and the patient is to date in complete remission.

\section{Discussion}

Breast lymphoma may mimic carcinoma because it has non-specific symptoms. Its most common clinical presentation is a painless mass without systemic symptoms such as fever, weight loss or sweating (20). The mammographic pattern is usually an oval high-density mass with well or partially defined margins, without calcifications (21). On ultrasound, breast lymphoma mass mostly appears oval or round in shape, homogeneous hypoechoic, commonly without apparent posterior attenuation (22). However, no specific mammographic or ultrasonographic imaging features may help to differentiate breast lymphoma from carcinoma or sarcoma. Thus, needle biopsy is necessary to achieve a correct diagnosis (1). FDG-PET/CT is recommended in 

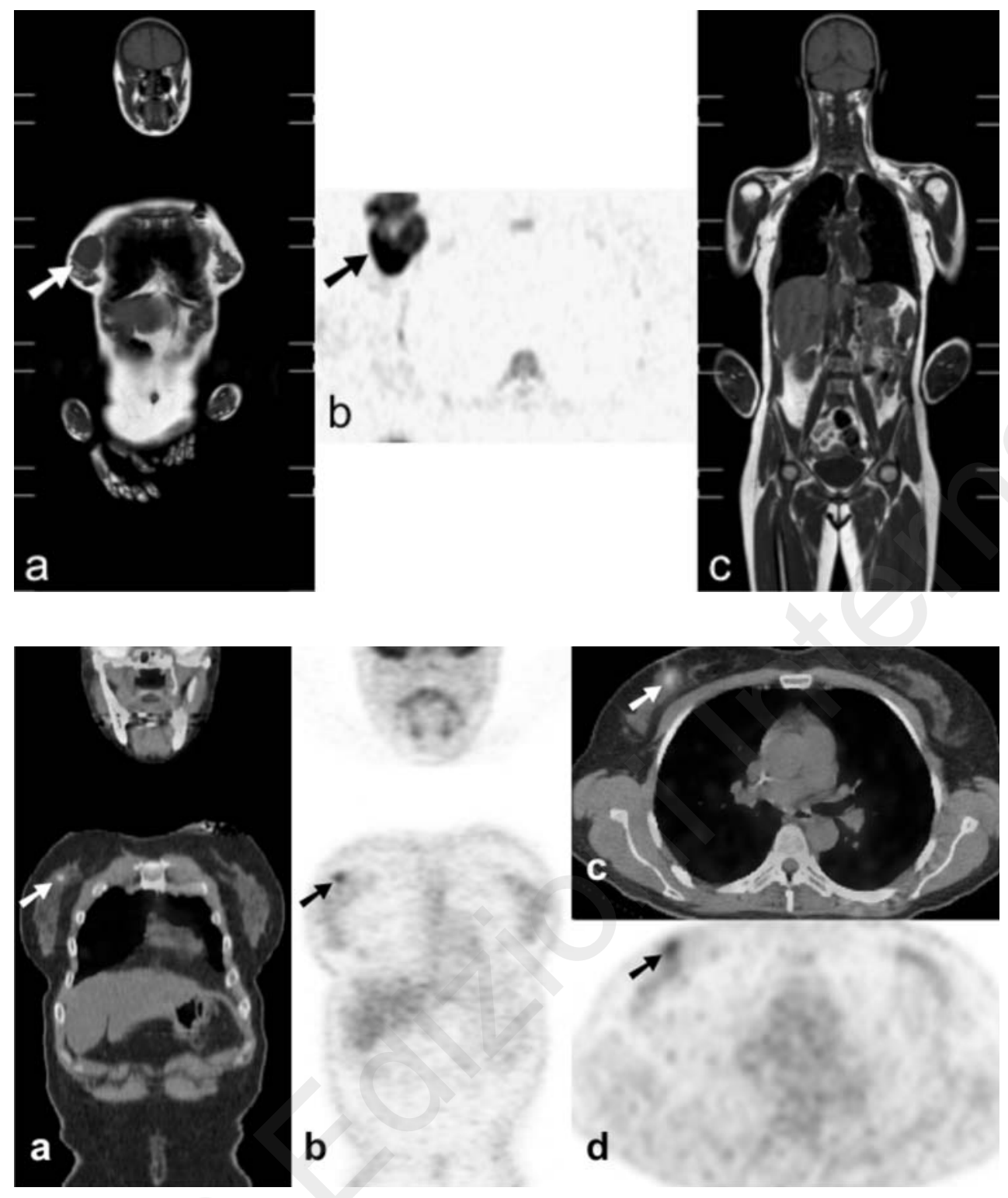

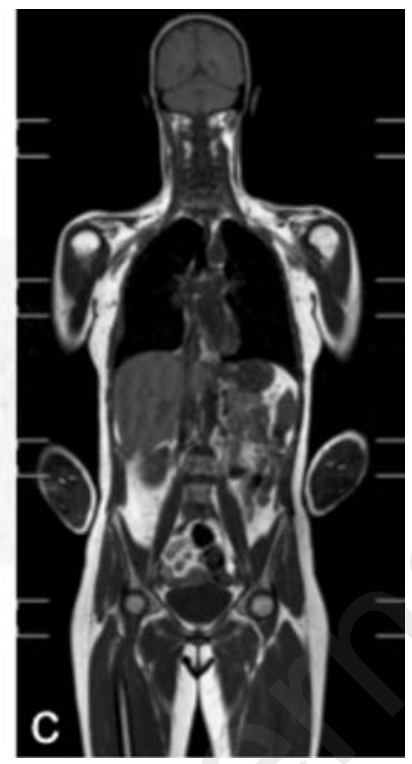

Figure 2 - WB-MR performed before treatment. Coronal WBMR T1-weighted image (a) shows a large right breast mass (arrows) with restricted pattern of diffusion on axial grey-scale inverted DWI image (b). Coronal WB-MR T1-weighted image (c) shows also the pathologic enlargement of the sixth right rib (circle).
DLBCL patients for staging and assessment of response to therapy (3). The five-point visual scale known as the Deauville criteria has been incorporated into the updated standard response criteria for DLBCL (3). The Deauville criteria depend on a qualitative comparison of FDG uptake in the lesions to that of the liver. Specifically, Deauville $>3$ on end-of-treatment FDG$\mathrm{PET} / \mathrm{CT}$ is considered as positive with a residual disease and a demonstrated worse cumulative survival rate (23), even if FDG uptake reduces from baseline (3). Previous studies demonstrated that this qualitative assessment on end-of-treatment FDG-PET/CT is reliable to predict the outcome of lymphoma patients and that minimal residual FDG uptake is not associated with high risk of relapse (24). However, it has been postu- lated that the use of rituximab, a monoclonal antibody against the protein CD20 used in B-cell lymphoma therapy, could lead to an increase of false positive end-oftreatment scans (25). Rituximab may lead to inflammatory changes with recruitment of immune cells, like the xanthogranulomatous process found in our patient, which might determine false positive FDG-PET/CT scans (25). Indeed, a xanthogranulomatous process is an inflammatory and reactive response with aspecific but characteristic findings such as the presence of granular, eosinophilic, PAS positive histiocytes, foamy macrophages, plasma cells, suppurative foci and hemorrhages (26). Post-therapy inflammatory changes may persist for up to 2 weeks after chemotherapy alone and for up to 2 or 3 months after radiotherapy (27). For 
A xanthogranulomatous process resembling residual disease on end-of-treatment 18f-FDG-PET/CT and Whole Body Magnetic Resonance performed on a primary breast lymphoma treated by ibrutinib plus rituximab-chop

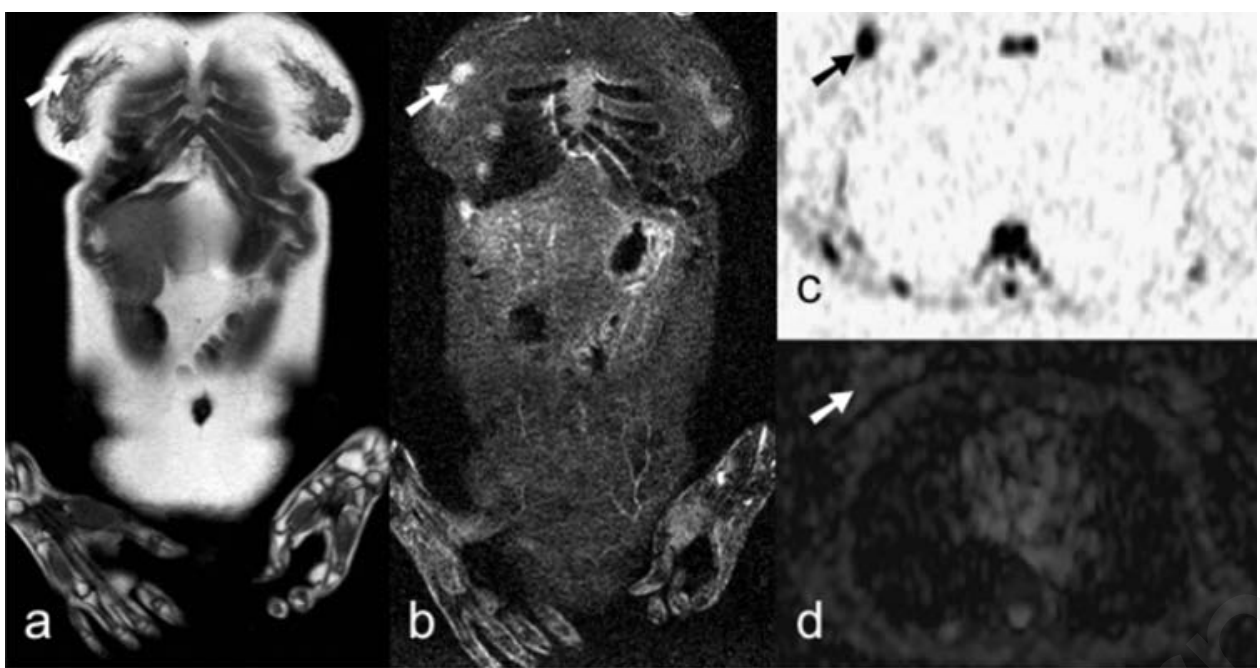

Figure 4 - WB-MR performed after treatment with ibrutinib plus rituximab-CHOP. Coronal T1-weighted (a) and T2-weighted STIR (b) images show a small nodule (arrows) within the right mammary gland with restricted pattern of diffusion on axial grey-scale inverted DWI image (c) and axial ADC map (d) images.

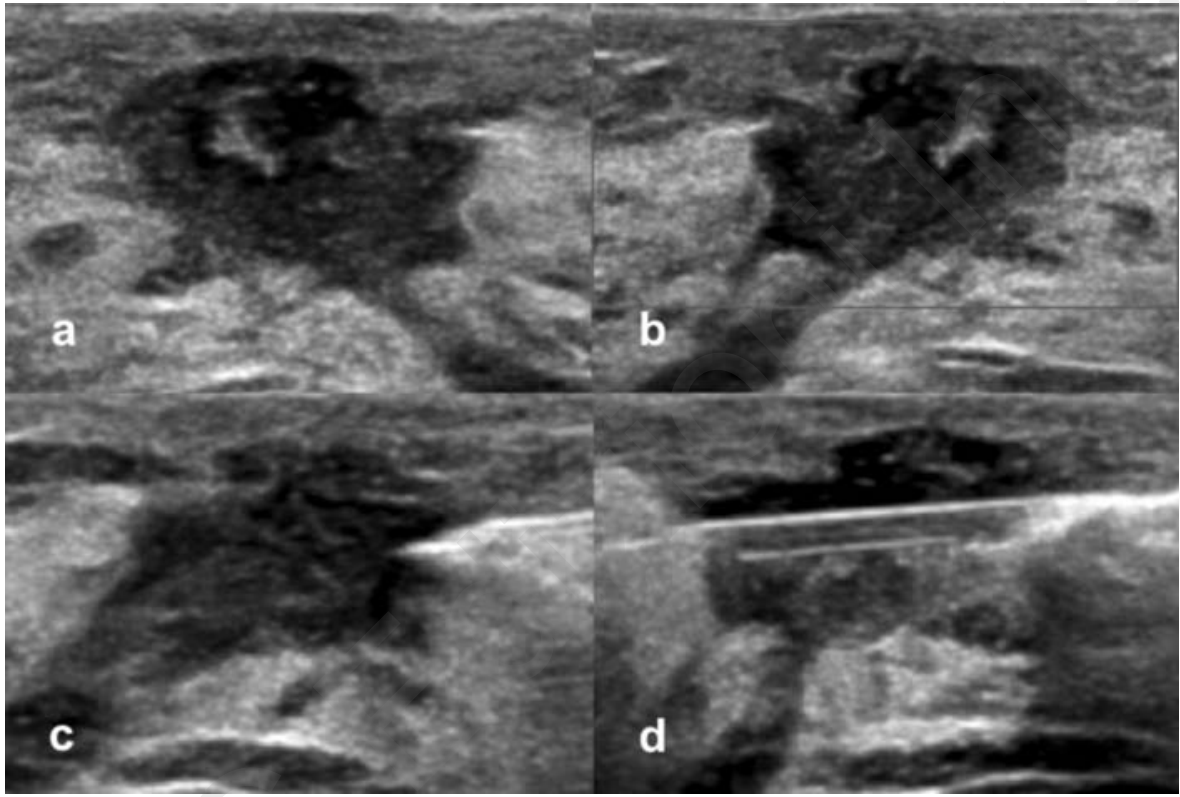

Figure 5 - Ultrasound-guided biopsy of the breast nodule after treatment. Ultrasound showed a solid inhomogenously hypoechoic nodule (a), without intralesional vascular flow on power-Doppler (b), that was biopsied using ultrasound guidance (c-d). this reason, end-of-treatment FDG-PET/CT is recommended 6 to 8 weeks after chemotherapy (27). Moreover, newer drugs, such as immunomodulatory agents and checkpoint inhibitors, have recently demonstrated high effectiveness on lymphoma, but are associated with unclear imaging features during and after treatment, such as tumor flare or pseudo-progression, which need to be subjects of future studies and they too are probably related to inflammatory reactions (28). One of these drugs is ibrutinib, an inhibitor of $\mathrm{B}$-cell receptor signaling pathway whose target is Bruton tyrosine kinase. Cheson et al. have recently introduced the term "Indeterminate Response" in order to identify and correctly manage such lesions characteri- zed by unclear clinical and imaging findings after treatment with drugs such as ibrutinib, suggesting to obtain a repeat imaging after an additional 12 weeks (29). WB-MR with DWI is a non-invasive imaging technique that avoids radiation exposure and contrast agent administration. The role of WB-MR, especially fused with PET in FDG-PET/MR, in breast cancer imaging is being investigated over the last few years, with promising preliminary results (29); instead, WB-MR has already a well-established role in lymphoma imaging. Its high contrast resolution enables an excellent evaluation of bone marrow, allowing a reliable evaluation marrow lymphomatous involvement (30) and the early identification of osteonecrotic lesions, which are 
very common in the follow-up of patients who receive chemotherapies and high doses of corticosteroids (3135). Furthermore, it provides functional information regarding tissue cellularity through DWI, which is a sequence probing the motion of water molecules in intra-cellular and inter-cellular spaces. Several studies have shown that it enables to differentiate benign lymph nodes from malignant ones $(16,36,37)$. Nevertheless, there is no consensus on the reliability and reproducibility of quantitative measurements on ADC map, with no standardization of pathologic ADC cut-off values in the evaluation of response to therapy. Recently, Mayerhoefer et al. have demonstrated that DWI, especially the rates of changes of minimum and mean ADC values, may be useful to predict complete remission in lymphoma patients treated by rituximab (37). However, it is well known that inflammatory reactions, besides determining an increased uptake of FDG, may display hyperintensity on high b-value DWI with a restricted pattern of diffusion on ADC map, mimicking a malignant tissue $(38,39)$.

\section{References}

1. Nicholson BT, Bhatti RM, Glassman L. Extranodal Lymphoma of the Breast. Radiol Clin North Am. 2016;54:711-26.

2. Gargano G, Agnese V, Calò V, Corsale S, Augello C, Bruno L, La Paglia L, Gullo A, Ottini L, Russo A, Fulfaro F, Rinaldi G, Crosta A, Cicero G, Majorana O, Palmeri L, Cipolla C, Agrusa A, Gulotta G, Morello V, Di Fede G, Adamo V, Colucci G, Tomasino RM, Valerio MR, Bazan V, Russo A; Gruppo Oncologico dell'Italia Meridionale: Detection and quantification of mammaglobin in the blood of breast cancer patients: can it be useful as a potential clinical marker? Preliminary results of a GOIM (Gruppo Oncologico dell'Italia Meridionale) prospective study. Ann Oncol. 2006 Jun;17 Suppl 7:vii41-5.

3. Sheikhbahaei S, Mena E, Pattanayak P, Taqhipour M, Solnes LB, Subramaniam RM. Molecular Imaging and Precision Medicine: PET/Computed Tomography and Therapy Response Assessment in Oncology. PET Clin. 2017;12:105-18.

4. Alongi P, Caobelli F, Gentile R, Stefano A, Russo G, Albano D, et al. Recurrent bladder carcinoma: clinical and prognostic role of 18 F-FDG-PET/CT. Eur J Nucl Med Mol Imaging. 2017;44:224-33.

5. Romano G, Agrusa A, Chianetta D, Frazzetta G, Sorce V, Di Buono G, Gulotta G. Laparoscopic management of adrenal tumors: A four-year experience in a single center. Minerva Chirurgica. 2014;69(2 SUPPL.1):125-129

6. Agrusa A, Romano G, Frazzetta G, Chianetta D, Sorce V, Di Buono G, Gulotta G. Laparoscopic adrenalectomy for large adrenal masses: single team experience. Int J Surg. 2014;12 Suppl 1:S72-4. doi: 10.1016/j.ijsu.2014.05.050.

7. Agrusa A, di Buono G, Chianetta D, Sorce V, Citarrella R, Galia M, Vernuccio L, Romano G, Gulotta G. Three-dimensional (3D) versus two-dimensional (2D) laparoscopic adrenalectomy: A case-control study. Int J Surg. 2016 Apr;28 Suppl 1:S114-7. doi: 10.1016/j.ijsu.2015.12.055.

\section{Conclusion}

In conclusion, wide imaging techniques availability improves diagnostic possibilities. However, the awareness of the adopted treatment strategy and its possible implications on imaging features is crucial to make a correct imaging and clinical assessment of response to therapy. Furthermore, a correct timing when performing nuclear medicine and radiology scans is essential to avoid a misinterpretation of imaging features, even if it is possible to have false positive findings for a long time, especially after newer therapies, as it was in our case.

\section{Conflicts of interest}

The Authors state that they have no conflict of interest.

\section{Disclosure of funding}

The Authors state that this work has not received any funding.

8. Cheson BD, Fisher RI, Barrington SF, Cavalli F, Schwartz LH, Zucca E, et al. Recommendations for initial evaluation, staging and response assessment of Hodgkin and Non-Hodgkin lymphoma: the Lugano classification. J Clin Oncol. 2014;32:3059-68.

9. Agrusa A, Romano G, Chianetta D, De Vita G, Frazzetta G, Di Buono G, Sorce V, Gulotta G. Right diaphragmatic injury and lacerated liver during a penetrating abdominal trauma: case report and brief literature review. World J Emerg Surg. $2014 \mathrm{Apr}$ 28;9:33. doi: 10.1186/1749-7922-9-33.

10. Agrusa A, Romano G, Di Buono G, Frazzetta G, Chianetta D, Sorce V, Billone V, Cucinella G, Gulotta G. Acute appendicitis and endometriosis: retrospective analysis in emergency setting. Giornale Italiano di Ostetricia e Ginecologia. 2013;35(6):728-732.

11. Agrusa A, Romano G, Salamone G, Orlando E, Di Buono G, Chianetta D, Sorce V, Gulotta L, Galia M, Gulotta G. Large cavernous hemangioma of the adrenal gland: Laparoscopic treatment. Report of a case. Int J Surg Case Rep. 2015;16:150-3. Doi:10.1016/j.ijscr.2015.09.040.

12. Agrusa A, Romano G, Dominguez LJ, Amato G, Citarrella R, Vernuccio L, Di Buono G, Sorce V, Gulotta L, Galia M, Mansueto P, Gulotta G. Adrenal cavernous hemangioma: which correct decision making process? Acta Medica Mediterranea. 2016;32(1):385-389.

13. Bonekamp S, Corona-Villalobos CP, Kamel IR. Oncologic applications of diffusion-weighted MRI in the body. J Magn Reson Imaging. 2012;35:257-79.

14. Giles SL, Messiou C, Collins DJ, et al. Whole-body diffusionweighted MR imaging for assessment of treatment response in myeloma. Radiology. 2014;271:785-94.

15. Galia M, Albano D, Narese D, Patti C, Chianca V, Di Pietto $\mathrm{F}$, et al. Whole-body MRI in patients with lymphoma: collate- 


\section{A xanthogranulomatous process resembling residual disease on end-of-treatment 18f-FDG-PET/CT and Whole Body Magnetic Resonance performed on a primary breast lymphoma treated by ibrutinib plus rituximab-chop}

ral findings. Radiol Med. 2016;121:793-800.

16. Albano D, Patti C, La Grutta L, Agnello F, Grassedonio E, Mulè A, et al. Comparison between whole-body MRI with diffusionweighted imaging and PET/CT in staging newly diagnosed FDGavid lymphomas. Eur J Radiol. 2016;85:313-8.

17. Albano D, Sinagra E, Patti C, Narese D, Agrusa A, Di Buono $\mathrm{G}$, et al. Caecal leiomyoma detected by whole-body MRI in a patient with Hodgkin lymphoma: first case report. G Chir. 2017 (in press).

18. Chen Y, Zhong J, Wu H, Chen N. The clinical application of whole-body diffusion-weighted imaging in the early assessment of chemotherapeutic effects in lymphoma: the initial experience. Magn Reson Imaging. 2012;30:165-70.

19. Hans PC, Weisenburger DD, Timothy C, et al. Confirmation of the molecular classification of diffuse large B-cell lymphoma by immunohistochemistry using a tissue microarray. Blood. 2004;103:275-82.

20. Kuper-Hommel MJ, Snijder S, Janssen-Heijnen ML, et al. Treatment and survival of 38 female breast lymphomas: a populationbased study with clinical and pathological reviews. Ann Hematol. 2003;82:397-404.

21. Lyou CY, Yang SK, Choe DH, Lee BH, Kim KH. Mammographic and sonographic findings of primary breast lymphoma. Clin Imaging. 2007;31:234-8.

22. Yang WT, Lane DL, Le-Petross HT, Abruzzo LV, Macapinlac HA. Breast lymphoma: imaging findings of 32 tumors in 27 patients. Radiology. 2007;245:692-702.

23. Fallanca F, Alongi P, Incerti E, et al. Diagnostic accuracy of FDG PET/CT for clinical evaluation at the end of treatment of HL and NHL: a comparison of the Deauville Criteria (DC) and the International Harmonization Project Criteria (IHPC). Eur J Nucl Med Mol Imaging. 2016;43:1837-48.

24. Manohar K, Mittal BR, Raja S, Bhattacharya A, Malhotra P, Varma S. Comparison of various criteria in interpreting end of therapy F-18 labeled fluorodeoxyglucose positron emission tomography/computed tomography in patients with aggressive nonHodgkin lymphoma. Leuk Lymphoma. 2013;54:714-719.

25. Han HS, Escalon MP, Hsiao B, Serafini A, Lossos IS. High incidence of false-positive PET scans in patients with aggressive non-Hodgkin's lymphoma treated with rituximab-containing regimens. Ann Oncol. 2009;20:309-318.

26. Cozzutto C, Carbone A. The xanthogranulomatous process. Xanthogranulomatous inflammation. Pathol Res Pract. 1988;183: 395-402.

27. Cheson BD, Pfistner B, Juweid ME, et al. Revised Response Criteria for Malignant Lymphoma. J Clin Oncol. 2007;25:579-86.

28. Cheson BD, Ansell S, Schwartz L, Gordon LI, Advani R, Jacene HA, et al. Refinement of the Lugano classification response criteria for lymphoma in the era of immunomodulatory therapy. Blood. 2016; pii: blood-2016-05-718528.
29. Sawicki LM, Grueneisen J, Schaarschmidt BM, et al. Evaluation of 18F-FDG PET/MRI, 18F-FDG PET/CT, MRI and CT in whole body staging of recurrent breast cancer. Eur J Radiol. 2016;85:459-65.

30. Albano D, Patti C, Lagalla R, Midiri M, Galia M. Whole-body MRI, FDG-PET/CT, and bone marrow biopsy, for the assessment of bone marrow involvement in patients with newly diagnosed lymphoma. J Magn Reson Imaging. 2017 Apr;45(4): 1082-1089.

31. Fosså A, Fiskvik IH, Kolstad A, et al. Two escalated followed by six standard BEACOPP in advanced-stage high-risk classical Hodgkin lymphoma: high cure rates but increased risk of aseptic osteonecrosis. Ann Oncol. 2012;23:1254-1259.

32. Granese R, Perino A, Calagna G, Saitta S, De Franciscis P, Colacurci N, Triolo O, Cucinella G. Gonadotrophin-releasing hormone analogue or dienogest plus estradiol valerate to prevent pain recurrence after laparoscopic surgery for endometriosis: a multi-center randomized trial. Acta Obstet Gynecol Scand. 2015 Jun;94(6):637-45. doi: 10.1111/aogs.12633.

33. Mainini G, Torella M, Di Donna MC, Esposito E, Ercolano S, Correa R, Cucinella G, Stradella L, Luisi A, Basso A, Cerreto FV, Cicatiello R, Matteo M, De Franciscis P. Nonhormonal management of postmenopausal women: effects of a red clover based isoflavones supplementation on climacteric syndrome and cardiovascular risk serum profile. Clin Exp Obstet Gynecol. 2013;40(3):337-41.

34. Albano D, Patti C, La Grutta L, et al. Osteonecrosis detected by Whole Body Magnetic Resonance in patients with Hodgkin Lymphoma treated by BEACOPP. Eur Radiol. 2016; doi:10.1007/s00330-016-4535-8.

35. Granese R, Adile G, Gugliotta G, Cucinella G, Saitta S, Adile B. Botox ${ }^{\oplus}$ for idiopathic overactive bladder: efficacy, duration and safety. Effectiveness of subsequent injection. Arch Gynecol Obstet. 2012;286(4): 923-929.

36. King AD, Ahuja AT, Yeung DK, et al. Malignant Cervical Lymphadenopathy: Diagnostic Accuracy of Diffusion-weighted MR Imaging. Radiology. 2007;245(3):806-813.

37. Mayerhoefer ME, Karanikas G, Kletter K, Kiesewetter B, Weber M, Rausch I, et al. Can Interim 18F-FDG PET or Diffusion-Weighted MRI Predict End-of-Treatment Outcome in FDG-Avid MALT Lymphoma After Rituximab-Based Therapy?: A Preliminary Study in 15 patients. Clin Nucl Med. 2016;41:837843.

38. Albano D, La Grutta L, Grassedonio E, et al. Pitfalls in whole body MRI with diffusion weighted imaging performed on patients with lymphoma: what radiologists should know. Magn Reson Imaging. 2016;34:922-931.

39. McDermott $S$, Skehan SJ. Whole body imaging in the abdominal cancer patient: pitfalls of PET-CT. Abdom Imaging. 2010;35:5569. 